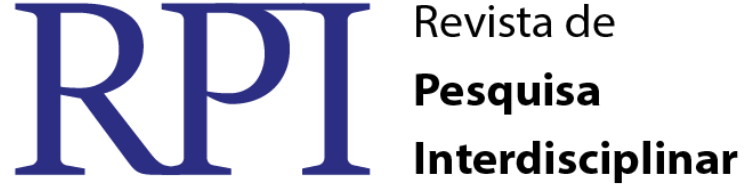

\section{RETAS PARALELAS, INTERDISCIPLINARIDADE, TRANSPOSIÇÃO DIDÁTICA E ESTÁGIO: UM PAPEL PARA A HISTÓRIA DA CIÊNCIA}

\author{
José Leonardo Tavares de Albuquerque ${ }^{1}$
}

\begin{abstract}
RESUMO
Neste artigo, será feita uma investigação do uso da proposta de inclusão da História da Ciência desenvolvida durante os estágios supervionados II e III do curso de Licenciatura em Física da referida instituição de Ensino Superior. Tendo tomado conhecimento da proposta em uma disciplina obrigatória do curso (Seminário de História e Filosofia da Ciência), pus-me a investigar como o uso dessa vertente do conhecimento humano poderia auxiliar no processo de ensino-aprendizagem de Física. A realização de tal perscrutação levou-nos a percepção das discussões atuais sobre o uso da história da ciência como auxiliar no processo de ensino e aprendizagem e sua importância na formação crítica cidadã, motivando o uso da mesma nas aulas de física no ensino médio durante a realização dos estágios supervisionados.
\end{abstract}

Palavras-chave: proposta, inclusão, estágios.

\section{PARALLEL LINES, INTERDISCIPLINARITY, DIDACTIC TRANSPOSITION AND INTERNSHIP: A ROLE FOR THE HISTORY OF SCIENCE}

\begin{abstract}
In this paper, it will be made an investigation about the use of History of Science inclusion proposal developed during the supervised internship II and III of the Physics graduation in the UFCG institution. Taking notice about the proposal in an obligatory discipline of the course (History Seminar and Philosophy of Science), I started to investigate how the use of this hillside of human knowledge could help in the process of Physics teaching and learning. The realization of this investigation led us to realize the current discussions about the use of history of science as an auxiliary in the process of teaching and learning and his important in the citizen critical formation, encouraging the use of the same in physics classes in high school during the realization of supervised internship.
\end{abstract}

Keywords: Proposal, Inclusion, Internships.

\section{INTRODUÇÃO}

Em nossa sociedade, contrariamente à da Idade Média, quando era a religião que tinha essa função, a ciência parece desempenhar o papel de mito fundamental, ou seja, que é para ela que as pessoas se dirigem para encontrar o que seria o real último. (FOUREZ, 1995, p. 55)

Esse movimento, denunciado por Fourez, é de fácil percepção. Todavia, há um paradoxo perceptível entre essa importância creditada à ciência e a quantidade de pessoas que atualmente se interessa pelo seu estudo. É fácil reconhecer esse paradoxo: percebem-se desinteresses massivos por parte de estudantes em aprender ciências na educação básica. $\mathrm{Na}$

\footnotetext{
${ }^{1}$ Universidade Federal de Campina Grande - CFP $\neg$ - Campus Cajazeiras. Licenciatura em Física
} 
educação superior encontra-se a vasilha de onde o problema finda e se alimenta cada vez mais: salas vazias em cursos de ciências naturais e áreas afins e salas cheias em áreas sociais e afins. Thomas Kuhn (2007) alerta para uma imagem errada da ciência que tem dominado não apenas o senso comum, como também os próprios cientistas devido, sobretudo, aos “[...] manuais que cada nova geração utiliza para aprender seu oficio" (KUHN, 2007, p. 19). Ainda, segundo o mesmo,

[...] um conceito de ciência deles haurido terá tantas possibilidades de assemelhar-se ao empreendimento que os produziu como a imagem de uma cultura nacional obtida através de um folheto turístico ou um manual de línguas (KUHN, 2007, p. 19).

Tem-se então o seguinte quadro atualmente: existe uma classe de conhecimentos, chamados de científicos, que estão no auge de sua importância perante a sociedade, porém o estudo de tais conhecimentos não tem atraído público, renovação. Certamente, esse problema passa pela dimensão do ensino. Vê-se um problema no ensino e na aprendizagem dos conhecimentos científicos sob os termos citados por Kuhn. O problema se deve em partes ao não reconhecimento de um fator que não é ministrado em manuais científicos: o fator humano. Retirar dos conhecimentos científicos sua raiz humana é como retirar de um relógio suas engrenagens. O grande mecanismo que chamamos de humanidade é constituído por pessoas. O trabalho de David Ausubel tem trazido, hodiernamente, à tona o papel ativo que as emoções desempenham na aprendizagem significativa (AUSUBEL, 2003).

Um movimento que vem expondo esta e outras necessidades no ensino das ciências é a chamada História da Ciência. Como conhecimento institucional a História da ciência é um evento recente, século XX, como conta Martins (MARTINS, 2001). Um ensino de ciências baseado na proposta da história da ciência visa conscientizar os estudantes do real desenvolvimento desse empreendimento humano, coletivo, socialmente construído que é a ciência; demonstrando como os seres humanos desenvolveram suas ideias abre portas para o entendimento e reconhecimento do trabalho dos cientistas e das dificuldades enfrentadas pela humanidade na construção deste tipo conhecimento cientifico. Como bem explicado por Martins,

Os livros científicos didáticos enfatizam os resultados aos quais a ciência chegou - as teorias e conceitos que aceitamos, as técnicas de análise que utilizamos - mas não costumam apresentar alguns outros aspectos da ciência. De que modo as teorias e os conceitos se desenvolvem? Como os

RPI Revista de Pesquisa Interdisciplinar, Cajazeiras, v. 1, Ed. Especial, 471 - 478, set/dez. de 2016. 
cientistas trabalham? Quais as ideias que não aceitamos hoje em dia e que eram aceitas no passado? Quais as relações entre ciência, filosofia e religião? Qual a relação entre o desenvolvimento do pensamento científico e outros desenvolvimentos históricos que ocorreram na mesma época? (MARTINS, 2006, p. 21)

Poder-se-ia argumentar se tal forma de ensino traria vantagens e estaria de acordo com teorias de aprendizagem em discussão hodierna. Pode-se dizer que reconhecidamente sim, pois a história da ciência revela, ao tratar dos cientistas e de como estes trabalham inseridos em uma bolha social e temporal, que o trabalho dos cientistas sofre muita influência das concepções prévias que estes possuem sobre o proposto. O estudo da história da ciência é capaz de conscientizar aqueles que se aventuram nele de que as características, valores, emoções humanas são indissociáveis do processo de construção de conhecimento e o ensino desses conhecimentos deve inegavelmente passar por esta dimensão. As concepções prévias (ou alternativas) (e seu papel) são então facilmente reconhecidas por historiadores da ciência, e por quem é assíduo na leitura desta, como fatores intrínsecos ao desenvolvimento de ideias. Martins explica então como aproveitar este momento para promover uma mudança conceitual dos estudantes em cordial acordo com a história da ciência:

Sob o ponto de vista da educação, a existência dessas concepções alternativas exige a utilização de novas estratégias. Os professores devem:

- conhecê-las e não fingir que não existem;

- não ridicularizá-las ou tentar recalcá-las, mas tratá-las com respeito;

- entender seu papel, sua fundamentação, para o indivíduo;

- compará-las com outras concepções - tanto a atualmente aceita pela ciência como outras alternativas;

- analisar as evidências a favor e contra cada uma delas; e

- tentar auxiliar o educando a passar por uma mudança conceitual, da antiga para a científica, através de argumentos da mesma natureza dos que são utilizados nas discussões científicas - mas não por um argumento de autoridade (MARTINS, 2006, p. 25).

Esse status que a ciência possui nos tempos hodiernos não está sendo utilizado de forma a explorar esse momento, pois se sim, estaríamos falando do sucesso do ensino das ciências sob todas as outras áreas do conhecimento humano, e não reconhecendo onde este ensino está falhando. Os estudantes podem facilmente reconhecer o papel desempenhado por 
esse tipo de conhecimento ao olhar não só ao seu redor, mas para o mundo (momento este oportunizado pela globalização - que é fruto direto do desenvolvimento cientifico) e perceber que certos mundos contados pela história escolar não existem mais. Algumas perguntas podem ser geradas por estudantes após realizarem este (e outros) reconhecimento (s): onde, quando, por quem e sob que circunstâncias se desenvolveram (ou tiveram início) os momentos que provocaram tais mudanças em escala global? Que sentimentos motivaram os cientistas a realizarem tais estudos? Essas e outras ad infinitum perguntas não são respondidas encarando o ensino desses conhecimentos via manuais.

Percebe-se, tem-se a sensação, durante a leitura de textos de história da ciência (feitos por historiadores da ciência, em especial), de que esta proposta se adéqua as diversas discussões (conhecimentos prévios, mudança conceitual, aprendizagem significativa, transposição didática etc.) em voga na atualidade no que concerne ao processo de ensino e aprendizagem. Esta sensação é legítima, até porque buscar entender como se deu o desenvolvimento dos conhecimentos científicos é sinônimo de entender como foi e como é realizado o trabalho dos cientistas, entre cientistas, melhor dizendo, de humanos e entre humanos envoltos em uma bolha social e temporal, e, como se nota facilmente, os humanos desenvolveram inúmeras ideias para entender outros humanos em seus contextos.

\section{História Da Ciência E Estágios Supervisionados}

Ter conhecido a história da ciência (de forma não muito profunda) ainda na graduação, tendo desenvolvido um amplo interesse sobre a mesma (aprofundamento nas leituras) e ter reconhecido nesta a maneira pela qual vinha desenvolvendo o aprendizado de física no curso em questão (e além dele) e ter tomado conhecimento da existência de que esta discussão já existia (a importância da história da ciência para o processo de ensino e aprendizagem) levoume diretamente a ideia de usar a proposta durante os estágios supervisionados com o intuito de auxiliar na formação crítica dos estudantes a respeito do mundo em que vivem. A eles então.

A abordagem e o entendimento metodológico proporcionados por Kuhn (KUHN, 2007) sobre o estudo das comunidades científicas, sobre os paradigmas, e como aquelas se comportam diante destes, e as revoluções causadas por mudanças paradigmáticas na ciência foram exploradas durante os estágios, tendo em vista o grande entendimento e organização proporcionada pelo seu uso.

RPI Revista de Pesquisa Interdisciplinar, Cajazeiras, v. 1, Ed. Especial, 471 - 478, set/dez. de 2016. 
Os estágios II e III, então, foram planejados levando em consideração, a História da Ciência. O campo de realização dos mesmos foi uma mesma escola, a EEEM Prefeito Joaquim Lacerda Leite, localizada na cidade de São José de Piranhas, cidade natal deste autor, $30 \mathrm{~km}$ de distância do Campus em questão, sob a orientação do professor Mestrando Gustavo de Alencar Figueiredo e sob supervisão do professor concedente Francisco Thiago Gomes de Oliveira. O tema central a ser desenvolvido nos estágios foi o eletromagnetismo, as turmas escolhidas sendo então a $3^{\text {a }}$ série do ensino médio da referida escola, sendo que o livro base usado era o livro de física do ensino médio dos autores Alvarenga \& Máximo. O tempo de cada estágio (na escola) foi de no mínimo 06 semanas (observação de aulas e prática pedagógica).

Deve-se ressaltar uma vez mais como o uso da história da ciência pode contribuir para o ensino de ciências, da física nesse caso, conforme Martins esclarece:

A história das ciências não pode substituir o ensino comum das ciências, mas pode complementá-lo de várias formas. O estudo adequado de alguns episódios históricos permite compreender as inter-relações entre ciência, tecnologia e sociedade, mostrando que a ciência não é uma coisa isolada de todas as outras, mas sim faz parte de um desenvolvimento histórico, de uma cultura, de um mundo humano, sofrendo influências e influenciando por sua vez muitos aspectos da sociedade. (MARTINS, 2006, p. 21-22).

Pode-se argumentar que alguma história da ciência, da física principalmente, é ministrada na educação básica, ao menos via professor ou via livros-texto. Mas será que está disciplina está sendo usada corretamente? Em tais livros a história da ciência se reduz a nomes, datas e anedotas, promovem concepções errôneas sobre o método científico e fazem uso de seu estudo em prol de argumentos de autoridade (MARTINS, 2006).

A etapa inicial do estágio, então, foi a análise do livro didático: O livro usado pela escola em questão não credita a história da ciência o mesmo papel que aqui se defende, conclui-se isso a partir da forma como esta disciplina é utilizada e disposta no livro: pequenas notas históricas que falam da vida de poucos cientistas dentro de tradições rubricadas (KUHN, 2007). Então, em termos de livro didático, os estudantes não têm a disposição informações sobre o desenvolvimento científico orientado historicamente dos temas constituintes ao eletromagnetismo, o que constitui uma perda colossal, pois tal revelaria como nenhum outro corpo de conhecimento científicos exemplos da construção humana não linear, baseado então em revoluções como nos conta Kuhn (ANO), do que hoje chamamos de eletromagnetismo. A segunda etapa foi a escolha dos temas: os temas que foram RPI Revista de Pesquisa Interdisciplinar, Cajazeiras, v. 1, Ed. Especial, 471 - 478, set/dez. de 2016. 
desenvolvidos em ambos os estágios foram os temas iniciais que costumam aparecer nos livros didáticos sobre o eletromagnetismo, desde as primeiras manifestações dos fenômenos elétricos até a ideia de campo. A terceira etapa foi a observação das aulas: durante esta etapa pode-se perceber (1) a não utilização da história da ciência durante a realização das aulas (o professor não tinha conhecimento do uso da proposta e de sua importância na época); a (2) dispersão dos estudantes durante as aulas era constante devido sobretudo ao uso da linguagem que a física faz uso e que é muito explorada no ensino médio: a matemática; outro ponto observado foi que (3) muitas dúvidas que os estudantes demonstraram ter poderiam ser solucionadas com o uso da história da ciência referente a esse conteúdo.

A quarta etapa foi a prática pedagógica em si.. Devido ao problema evidente do mau uso desta pelo livro didático, foi organizado por um texto, com base em um livro organizado por historiadores da ciência e/ou autores que conhecem tal disciplina (ROCHA, 2002), que abordava o desenvolvimento dos temas a serem desenvolvidos pelo viés da história da ciência, tendo em mente os perigos de se realizar tal tarefa, como deixa claro Martins (MARTINS, 2001). Além desse texto, foram entregues dois fragmentos retirados do livro citado que abordavam a "lei de Coulomb" e a ideia de Campo de Michael Faraday. Cada estudante recebeu os materiais preparados. Cabe aqui ressaltar a ajuda recebida pelo organizador do livro em questão, Me. José Fernando Moura Rocha, onde, após contatá-lo via e-mail, o mesmo me respondeu e enviou-me artigos de sua autoria sobre os temas em questão que me auxiliou enormemente nas atividades desenvolvidas sob tal perspectiva.

Nos estágios os textos foram entregues durante a primeira a aula, fazendo uma leitura acompanhada com os mesmos, usando sempre que necessário slides para ilustração de conceitos, experimentos ou imagens de personagens (algo que se mostrou muito eficaz). $\mathrm{O}$ prosseguimento das aulas foi então firmado nesses termos. Perguntas e dúvidas surgiram com muita frequência e foi possível, graças ao uso da história da ciência, responder a todas. A leitura inicial proporcionou aos estudantes uma visão das primeiras tentativas de responder aos fenômenos que envolviam o âmbar (ou eléktron, em grego), fazendo-os perceber que antes de existirem paradigmas universalmente aceitos há, sim, a presença de uma multiplicidade de concepções e modelos que visam explicar ao menos alguns dos efeitos observados (KUHN, 2007).

Um movimento que só pode ser desenvolvido usando-se história da ciência é a realização de questionários. Somente no estágio III está ideia foi percebida e então foi pedido, antes da explicação de qualquer conteúdo, que os estudantes explicassem os fenômenos que 
presenciaram (foi atritado contra uma folha de papel um canudo de plástico e este foi fixado na parede por indução eletrostática; uma régua atritada da mesma forma atraia pedaços de papel). Alguns estudantes responderam, outros não. Algumas respostas foram muito interessantes: algumas corretas (tendo em vista a atual explicação para o fenômeno); outras envolveram o atrito como o responsável, onde a diferença de temperatura foi vista como responsável pela atração; em outras pude perceber que alguns estudantes foram influenciados por conhecimentos prévios, fazendo analogia com um imã ou afirmando que foi criado um imã temporário e/ou mesclando conceitos, como densidade e polaridade ("diferença de polaridade" gerando atração); em nenhuma das respostas os elétrons foram citados como os responsáveis pelos fenômenos (eletrização por atrito e por indução) (ALBUQUERQUE ${ }^{(2)}$, 2015). As respostas proporcionaram momentos de discussões dos modelos.

Foi (e é) possível também (graças ao acompanhamento desenvolvido pela história da ciência): (1) demonstrar que parte da terminologia atual que se usa no eletromagnetismo é derivada de processos (de analogias usadas a classificações de cada modelo) que se dão dentro dessas tentativas (históricas) de explicação, como é (ou foi) o caso da terminologia de carga elétrica, do elétron (do radical "eletr" em si, do grego eléktron, âmbar), do campo elétrico, das ideias de condutores e isolantes etc.; (2) explicar a importância dos experimentos e as suas reais finalidades (estes nem sempre eram aplicações conceituais, mas sim responsáveis pelas próprias evoluções conceituais); (3) proporcionar momentos de reflexão acerca da construção dos conhecimentos científicos.

Algo que deve ser esclarecido é o uso da matemática. Muita resistência é oferecida por professores ao uso da História da ciência por estes pensarem que as aulas apenas envolvem contextos históricos e nenhuma matemática, porém é ilegítima tal afirmação. Pelo contrário, a história da ciência pode propiciar momentos de justificação da matemática desenvolvida no eletromagnetismo, como é o caso da força elétrica, do campo elétrico, do potencial elétrico etc. Alguns estudantes (em ambos os estágios) fizeram objeções acerca do uso da proposta, queixando-se da quantidade de informações ministradas em detrimento do pouco tempo, porém, o momento foi utilizado para discutir sobre a necessidade de fazer tais estudos e, depois de um esclarecimento sobre como estes seriam avaliados (a avaliação levou em consideração a história da ciência), estes ficaram mais adeptos ao prosseguimento da proposta (ALBUQUERQUE ${ }^{(1)}$, 2015). Adotando esta postura percebe-se claramente uma maior participação dos estudantes e um sentimento de confiança mais amplo por parte dos mesmos 
em suas aprendizagens ao reconhecerem a humanidade em algo que se mostrava antes tão improvável de entendimento.

\section{Considerações Finais}

Um conceito geométrico muito explorado (como comparativo) em diálogos é o paralelismo entre retas. As características geométricas exploradas de duas retas paralelas são: (1) não possuir pontos em comum; (2) duas retas paralelas possuírem a mesma direção. Os contrários a estas também sendo explorados. Uma vez mais estas características serão aqui usadas na defesa de que história da ciência e interdisciplinaridade desfrutarem da segunda condição: ambas as propostas possuem a mesma direção de entendimento, pois é cobrado de quem se dedica ao uso da história da ciência conhecimentos vastos que perpassam todas as áreas do conhecimento humano (movimento inclusive percebido pelos estudantes (ALBUQUERQUE $\left.{ }^{(1)}, 2015\right)$ ), confluindo assim para o ideário do ensino interdisciplinar tão visado em tempos de fragmentação do conhecimento humano (MORIN, 2000). "O "trabalho" que faz de um objeto de saber a ensinar, um objeto do ensino, é chamado de transposição didática” (CHEVALARD, 1991, p.31). A história da ciência pode então auxiliar, como nenhum outro conhecimento, neste "trabalho" de transposição didática abordado por Chevalard, ensinando, por meio de sua leitura, como foram desenvolvidos os momentos que proporcionaram aos humanos ser a espécie mais adaptável de todas e alcançar o status atual.

Os momentos de aprendizagem proporcionados pelo uso da história da ciência durante o desenvolvimento dos estágios se mostraram muito frutíferos, contribuindo para o ensino dos temas iniciais do eletromagnetismo, incentivando os estudantes e o professor a realizarem este processo diante dos próximos aprendizados. Este é o maior dos ensinamentos (na visão deste autor) que a história da ciência pode dar ao ensino das ciências: conscientizar-nos acerca da condição na qual nos encontramos neste mundo, principalmente a (condição) humana (MORIN, 2000).

\section{REFERÊNCIAIS}

RPI Revista de Pesquisa Interdisciplinar, Cajazeiras, v. 1, Ed. Especial, 471 - 478, set/dez. de 2016. 
ALBUQUERQUE, J. L. T. Relatório de estágio supervisionado II. 2015. 132 f. Estágio supervisionado. UFCG, Cajazeiras, 2015.

ALBUQUERQUE, J. L. T. Relatório de estágio supervisionado III. 2015. 150 f. Estágio supervisionado. UFCG, Cajazeiras, 2015.

ALVARENGA, Beatriz; MÁXIMO, Antônio. Física: contexto e aplicações. Editora Scipione, São Paulo, 2014.

AUSUBEL, D. P. Aquisição e retenção de conhecimentos: uma perspectiva cognitiva. Lisboa: Plátano, 2003.

CHEVAllaRD, Y. La Transposición Didáctica: del saber sabio al saber enseñado. Argentina: Editorial Aique, 1991.

FOUREZ, Gérard. A construção das ciências: introdução à filosofia e à ética das ciências. São Paulo: Editora Universidade Estadual Paulista, 1995.

KUHN, Thomas. S. A estrutura das revoluções científicas. São Paulo: Perspectivas, 1975. MARTINS, Roberto de Andrade. Como não se escrever sobre história da física - um manifesto historiográfico. Revista Brasileira de Ensino de Física, vol. 23, nº 1, p. 113-129, Março de 2001.

MARTINS, Roberto de Andrade. História e história da ciência: encontros e desencontros. Pp. 11-46, in: Actas do $1^{o}$. Congresso Luso-Brasileiro de História da Ciência e da Técnica (Universidade de Évora e Universidade de Aveiro). Évora: Centro de Estudos de História e Filosofia da Ciência da Universidade de Évora, 2001.

MARTINS, Roberto de Andrade. INTRODUÇÃO. A história das ciências e seus usos na educação. Pp. xxi-xxxiv, in: SILVA, Cibelle Celestino (ed.). Estudos de história e filosofia das ciências: subsídios para aplicação no ensino. São Paulo: Livraria da Física, 2006.

MORIN, Edgar. Os sete saberes necessários a educação do futuro. 8.ed. São Paulo: Cortez; Brasília, DF: UNESCO, 2000.

ROCHA, José Fernando M. (Org.). Origem e Evolução das Idéias da Física. Salvador: EDUFBA, 2002. 